\title{
ANALYSIS OF ANGULAR DEFORMITIES ON RADIOGRAPHS
}

\author{
H. F. BÄR, H. BREITFUSS
}

We agree with Floyd (1988) that, while the measurement on radiographs of single plane deformities can be accurate, that of 'two-plane deformities' cannot without assistance. We have therefore developed a simple method of estimating these two-plane deformities and use it routinely in our department. Two radiographs and a nomogram are the only requirements for determining the true angle of deformity (which routinely exceeds the angle measured in one plane) and its orientation. The method is based on Pythagoras' theorem and was first published by Pogglitsch (1977). It depends on the fact that somewhere between the coronal and sagittal planes, there is one plane in which the angle of deformation is correctly shown at its maximum.

Method. The apparent coronal and sagittal angles of deformity are measured on anteroposterior and lateral radiographs respectively. The sagittal angle is inserted on the $x$-axis (horizontal) of the nomogram and the coronal angle on the $y$-axis (vertical). The point where they meet in the $x-y$-plane is determined and the resulting

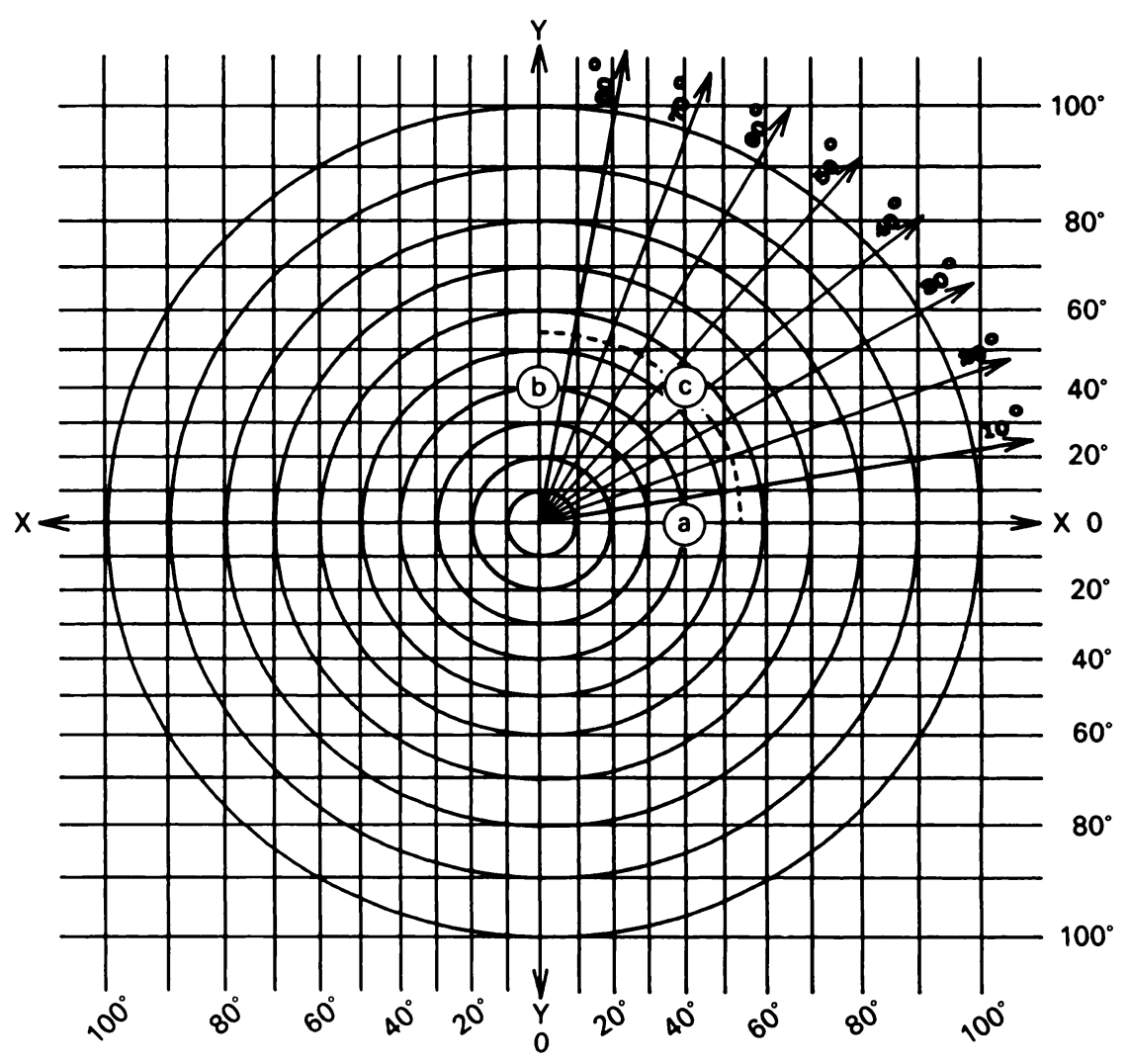

Fig. 1

Nomogram to determine amount and orientation of a 'two-plane deformity'.

H. F. Bär, Dipl-Ing (FH), Assistenzarzt

H. Breitfuss, Dr med, Assistenzarzt,

Department of Surgery, Ruhr-University Bochum, PO Box 100250 , D-4630 Bochum 1. West Germany.

Correspondence to $\mathrm{Mr} \mathrm{H}$. F. Bär.

(C) 1989 British Editorial Society of Bone and Joint Surgery $0301-620 X / 89 / 4 R 29 \$ 2.00$

J Bone Joint Surg [Br] 1989:71-B:710 1 vector (the radius from the zero point) then shows the true angle and amount of deformity. In Figure 1 for example, the letter ' $a$ ' shows a single-plane deformity of $40^{\circ}$ in the sagittal plane, ' $b$ ' a deformity of $40^{\circ}$ in the coronal plane. The letter ' $c$ ' represents the deformity which would give both ' $a$ ' and ' $b$ ': its amount, read on the $\mathrm{x}$-axis or the $\mathrm{y}$-axis is between $50^{\circ}$ and $60^{\circ}$, and its 
Table I. The amount of the true angle of deformity (upper table) and the plane of its true orientation (lower)

\begin{tabular}{|c|c|c|c|c|c|c|c|c|c|c|}
\hline \multirow{2}{*}{$\begin{array}{l}\text { Coronal } \\
\text { angle }\end{array}$} & \multicolumn{10}{|c|}{ Sagittal angle } \\
\hline & 2.0 & 4.0 & 6.0 & 8.0* & 10.0 & 12.0 & 14.0 & 16.0 & 18.0 & 20.0 \\
\hline $\begin{array}{c}2.0 \\
4.0 \\
6.0^{*} \\
8.0 \\
10.0 \\
12.0 \\
14.0 \\
16.0 \\
18.0 \\
20.0\end{array}$ & $\begin{array}{r}2.8 \\
4.5 \\
6.3 \\
8.3 \\
10.2 \\
12.2 \\
14.2 \\
16.2 \\
18.3 \\
20.3\end{array}$ & $\begin{array}{r}4.5 \\
5.7 \\
7.2 \\
9.0 \\
10.8 \\
12.7 \\
14.6 \\
16.6 \\
18.6 \\
20.6\end{array}$ & $\begin{array}{r}6.3 \\
7.2 \\
8.5 \\
10.0 \\
11.7 \\
13.5 \\
15.3 \\
17.2 \\
19.1 \\
21.1\end{array}$ & $\begin{array}{c}8.3 \\
9.0 \\
10.0^{*} \\
11.3 \\
12.8 \\
14.5 \\
16.2 \\
18.0 \\
19.8 \\
21.7\end{array}$ & $\begin{array}{l}10.2 \\
10.8 \\
11.7 \\
12.8 \\
14.2 \\
15.7 \\
17.3 \\
19.0 \\
20.7 \\
22.6\end{array}$ & $\begin{array}{l}12.2 \\
12.7 \\
13.5 \\
14.5 \\
15.7 \\
17.0 \\
18.5 \\
20.1 \\
21.8 \\
23.5\end{array}$ & $\begin{array}{l}14.2 \\
14.6 \\
15.3 \\
16.2 \\
17.3 \\
18.5 \\
19.9 \\
21.4 \\
23.0 \\
24.6\end{array}$ & $\begin{array}{l}16.2 \\
16.6 \\
17.2 \\
18.0 \\
19.0 \\
20.1 \\
21.4 \\
22.8 \\
24.3 \\
25.8\end{array}$ & $\begin{array}{l}18.3 \\
18.6 \\
19.1 \\
19.8 \\
20.7 \\
21.8 \\
23.0 \\
24.3 \\
25.7 \\
27.2\end{array}$ & $\begin{array}{l}20.3 \\
20.6 \\
21.1 \\
21.7 \\
22.6 \\
23.5 \\
24.6 \\
25.8 \\
27.2 \\
28.6\end{array}$ \\
\hline \multirow{2}{*}{$\begin{array}{l}\text { Coronal } \\
\text { angle }\end{array}$} & \multicolumn{10}{|c|}{ Sagittal angle } \\
\hline & 2.0 & 4.0 & 6.0 & $8.0^{*}$ & 10.0 & 12.0 & 14.0 & 16.0 & 18.0 & 20.0 \\
\hline $\begin{array}{c}2.0 \\
4.0 \\
6.0^{*} \\
8.0 \\
10.0 \\
12.0 \\
14.0 \\
16.0 \\
18.0 \\
20.0\end{array}$ & $\begin{array}{l}45.0 \\
63.4 \\
71.6 \\
76.0 \\
78.7 \\
80.6 \\
81.9 \\
82.9 \\
83.7 \\
84.3\end{array}$ & $\begin{array}{l}26.6 \\
45.0 \\
56.3 \\
63.5 \\
68.2 \\
71.6 \\
74.1 \\
76.0 \\
77.6 \\
78.8\end{array}$ & $\begin{array}{l}18.4 \\
33.7 \\
45.0 \\
53.1 \\
59.1 \\
63.5 \\
66.9 \\
69.5 \\
71.7 \\
73.4\end{array}$ & $\begin{array}{l}14.0 \\
26.5 \\
36.9^{*} \\
45.0 \\
51.4 \\
56.4 \\
60.3 \\
63.5 \\
66.2 \\
68.4\end{array}$ & $\begin{array}{l}11.3 \\
21.8 \\
30.9 \\
38.6 \\
45.0 \\
50.2 \\
54.5 \\
58.1 \\
61.1 \\
63.6\end{array}$ & $\begin{array}{r}9.4 \\
18.4 \\
26.5 \\
33.6 \\
39.8 \\
45.0 \\
49.4 \\
53.2 \\
56.4 \\
59.2\end{array}$ & $\begin{array}{r}8.1 \\
15.9 \\
23.1 \\
29.7 \\
35.5 \\
40.6 \\
45.0 \\
48.9 \\
52.2 \\
55.1\end{array}$ & $\begin{array}{r}7.1 \\
14.0 \\
20.5 \\
26.5 \\
31.9 \\
36.8 \\
41.1 \\
45.0 \\
48.4 \\
51.4\end{array}$ & $\begin{array}{r}6.3 \\
12.4 \\
18.3 \\
23.8 \\
28.9 \\
33.6 \\
37.8 \\
41.6 \\
45.0 \\
48.1\end{array}$ & $\begin{array}{r}5.7 \\
11.2 \\
16.6 \\
21.6 \\
26.4 \\
30.8 \\
34.9 \\
38.6 \\
41.9 \\
45.0\end{array}$ \\
\hline
\end{tabular}

* If the angle in the sagittal plane is (for example) $8^{\circ}$ and the coronal angle is $6^{\circ}$ then the true angle of deformity is $10^{\circ}$; the orientation of the true angle of deformity is $36.9^{\circ}$ from the sagittal plane

orientation to the sagittal plane is $45^{\circ}$. If in this example ' $a$ ' represented backward angulation and ' $b$ ' a varus deformity, then forward angulation and valgus deformity would have been on the opposite side of the axes. The result can also be obtained (with greater accuracy) by using a table (Table I) or a personal computer, with or without a graphics tablet (Breitfuss, Schneider and Röschel 1986).

Discussion. We would like to emphasise that coronal and sagittal deformities need not be used in a strictly anatomical sense; the important requirements are: reproducible individual landmarks on pre- and intraoperative radiographs; and radiographs taken accurately at $90^{\circ}$ to each other with the patient remaining still.

The method is useful in research as well as in clinical situations such as the planning of osteotomies. As presented here it cannot be used for the evaluation of rotational deformities.

No benefits in any form have been received or will be received from a commercial party related directly or indirectly to the subject of this article.

\section{REFERENCES}

Breitfuss H, Schneider H, Röschel O. Die Berechnung des wahren Winkels bei Fehlstellungen des Skelettsystems mit elektronischer Datenverarbeitung. Retrospektive Studie von 53 mit Achsenfehlstellung geheilten kindlichen Oberschenkelschaftbrüchen. Unfallchirurgie 1986;12:305-11. (Eng. Abstr.)

Floyd AS. Is the measurement of angles on radiographs accurate? $J$ Bone Joint Surg [ Br] 1988:70-B:486-7.

Pogglitsch H. The derivation from X-rays of the "true angles" of the skeleton system. Unfallchirurgie 1977:3:155-7. (Eng. abstr.) 